Artículo de Opinión

REV EXP MED

2019;5(2).

Abril - Junio

\title{
¿Realmente Enterovirus D68 podría estar relacionado con el brote del Síndrome de Guillain Barré en Perú?
}

\author{
Could enterovirus d68 be related to Guillain Barré syndrome in Peru?
}

\author{
Franklin R. Aguilar-Gamboa ${ }^{1 a}$
}

A finales de otoño de 2019 un incremento en el número de casos del síndrome de Guillain barré (SGB) fue reportado en 20 departamentos del Perú, afectando en su mayoría a las regiones costeras del norte: Cajamarca, Junín y Lima. La información que se tiene respecto a la causa de este brote aún es muy limitada, considerando que dicho síndrome puede ser desencadenado por vacunaciones, intervenciones quirúrgicas e infecciones víricas o bacterianas previas. Sin embargo está circulando información en los medios de comunicación, personal asistencial e incluso en protocolos del ministerio de salud, acerca de la probable relación entre los Enterovirus (EV), principalmente el D68, con esta patología. Esta afirmación se está convirtiendo en el común de las declaraciones por parte del personal de salud en los medios de comunicación, y se basa en el hallazgo de estos virus en heces y líquido cefalorraquídeo (LCR) de pacientes con SGB notificados en 2018 por el Instituto Nacional de Salud del Perú (INS) procedentes de la ciudad de Trujillo-Perú (1). Ante ello deseo exponer ciertas imprecisiones que se estarían dando respecto a este tema, con el objetivo de contribuir a la mejora de las estrategias en la búsqueda de un agente causal (si es que lo hubiese), describir en que patologías se encuentran relacionados los EV e interpretar adecuadamente su hallazgo en muestras clínicas.

Según la Organización Mundial de la Salud (OMS), el SGB es una enfermedad en la cual el sistema inmunitario del propio organismo ataca parte del sistema nervioso periférico, afectando nervios que controlan los movimientos musculares así como a los que transmiten sensaciones dolorosas, térmicas y táctiles. Esto puede producir debilidad muscular y pérdida de sensibilidad en las extremidades. Así mismo, afecta a personas de todas las edades. Sin embargo, reconoce un riesgo levemente mayor si el paciente es varón, y adulto joven (2). EI SGB es un trastorno post-infeccioso típico desencadenado por algunas bacterias y virus, así como causas no infecciosas como vacunas ${ }^{(3)}$. A su vez, si revisamos información publicada por la OMS encontraremos que en los últimos años se enfatiza la relación hallada con el virus zika (2), mientras que el Centro de Control de Enfermedades (CDC) investiga la relación del SGB con vacunas como la de influenza (4). Sin embargo ninguna de estas entidades referentes en salud hace mención al EV como causa probable. Entonces, como causa probable: ¿por qué se hace referencia a los EV en tiempos de brote del SGB? ¿Dónde se originó esta idea?.

Si buscamos en la web, encontraremos que el único lugar en el mundo donde se menciona esta probable relación, es en el Perú. Y fue a finales de mayo de 2018 que representantes del INS, detectaron de manera preliminar la presencia de un EV en muestras de secreción de líquido cefalorraquídeo y heces de pacientes con problemas neurológicos y del que se esperaba tener la identificación exacta tras un proceso de genotipificación del cual a la fecha no se conoce resultado (5). Luego, el 16 de agosto del 2018 el Ministerio de Salud del Perú emitió la resolución directoral N0177-2018-DG-HEJCU donde aprueba "el plan de contingencia para la atención de pacientes sospechosos del síndrome de Guillain barré del hospital de emergencias José Casimiro Ulloa"(6), en el que se describen los agentes infecciosos relacionados con el SGB, para lo cual citan el estudio de Jacobs et al. 1998 (7), sin embargo es curioso que en el plan mencionan a "Enterovirus", incluso

\footnotetext{
1. Laboratorio de Inmunología y virología. Dirección de investigación del Hospital Regional Lambayeque. Lambayeque, Perú. a. Biólogo Microbiólogo
} 
al EV-D68 como hallazgo del estudio de Jacobs, cuando en realidad éste no lo hace en ninguna de sus líneas. Así mismo, también se hace referencia de brotes de SGB relacionados al EV-D68 para lo cual citan a Willians et al $2016{ }^{\left({ }^{8}\right)}$. Sin embargo, en este estudio se describe un SGB atípico en 10 adultos, los cuales no tuvieron relación directa sino que coincidieron temporalmente ( 3 meses) en la misma ciudad con un grupo de cuatro niños con parálisis flácida aguda y en dos de ellos se aisló a EV-D68. Lo cual a mi opinión está lejos de ser un estudio que demuestre relación.

Entonces ¿porque insistir con esta probable relación que carece de antecedentes previos? Pues al parecer, el término parálisis flácida (PF), estaría ocasionando alguna confusión, lo cual sería el origen de estas imprecisiones. Ante ello, es necesario mencionar que la PF es una definición operativa, enmarcada en la campaña de la OMS, de la década de los ochenta, con el objetivo de erradicar la polio del mundo, por lo que se intentaba incluir con esta definición a todos los casos de probable poliomielitis. Entonces la PF está referida a una serie de enfermedades de causalidad múltiple, sin embargo estudios como los de Maloney et al. 2015 (9) (el cual es citado en el protocolo mencionado líneas arriba) contribuyen a generar concluciones imprecisas al hacer referencia que los casos de PF coincidieron con un brote de EV-D68, sin mencionar si fueron casos de SGB u otra patología dentro de la PF. Esto resalta la necesidad de conocer que existen dos enfermedades muy parecidas al SGB dentro de la definición de PF: La mielitis aguda flácida (AFM, por sus siglas en inglés) y la mielitis aguda transversa, en las cuales los EV sí parecen jugar un rol primordial y existe mucha evidencia científica sobre ello.

En 2014 el EV-D68 produjo uno de los más grandes brotes de infecciones respiratorias en EE. UU en el que se diagnosticó la AFM en el 10,4\% de afectados. A propósito de ello, investigadores australianos y estadounidenses confirmaron la relación de éste tipo de parálisis con el virus ${ }^{(10)}$; sin embargo, en este brote no se reportó casos de SGB.

Respecto al reconocimiento de estos tipos muy similares de PF, Nelson et al 2016. Realiza importantes precisiones al respecto describiendo que: "La AFM representa un subconjunto único de parálisis flácida aguda distinta de la SGB y la mielitis transversa. EI SGB suele presentarse con una parálisis ascendente y puede asociarse con parálisis facial y síntomas sensoriales. Los niños con mielitis transversa tienen debilidad y pérdida sensorial prominente, a menudo se manifiestan como un nivel sensorial espinal. En contraste, la mayoría de los niños con AFM tienen parálisis focal de la médula espinal similar a la poliomielitis con un mínimo o ningún síntoma sensorial' (11). Entonces, a pesar de que EVD68 es causa reconocida de AFM, no podemos extrapolar estos hallazgos hacia el SGB, el cual tiene un carácter fuertemente post infecciosos y no concomitante, a diferencia de mielitis transversa y AFM que sí parecerían tenerlo.
Conocido el rol de los EV-D68 en las enfermedades neurológicas si deseamos hallar relación de causalidad debemos emplear e interpretar adecuadamente las pruebas de laboratorio en el marco de la búsqueda de un probable agente infeccioso. En este sentido, el estudio más importante respecto al origen post infeccioso del SGB, fue realizado por Jacob en 1998, en el cual se describen las frecuencias de anticuerpos frente a las especies que hoy en día relacionamos con el síndrome. Es importante señalar que este estudio sigue vigente hasta nuestros días y citado aún por el CDC y la OMS por investigar la respuesta serológica del paciente entendiendo al SGB como consecuencia más que como resultado de una infección directa o concomitante en la que deba hallarse un agente infeccioso in situ (criterio que s sería oportuno cuando estamos frente a mielitis transversa y AFM). Así mismo, la estrategia de buscar un agente etiológico en diferentes muestras (heces, LCR, secreciones respiratorias y sangre) es apropiada ante un caso de PF de origen desconocido y debemos procurar seguir haciéndolo. Pero también es primordial comprender que su mayor rendimiento o beneficio se obtendrán en la vigilancia frente a poliomielitis, la mielitis transversa, AFM y casos de meningitis aséptica. Pero si se trata de hallar relación entre SGB y algún tipo de EV necesitaríamos herramientas diagnósticas adicionales.

Los estudios en biología molecular para la detección de EV-D68 en muestras clínicas son la mejor herramienta para detección de este agente infeccioso. Sin embargo ¿el hallar al agente etiológico in situ demostraría causalidad en una enfermedad con un fuerte componente autoinmune? Es reconocido que en el SGB los auto-anticuerpos que se producirían como resultado del mimetismo molecular son los responsables del daño de la vaina de mielina que sufren los axones en el SNP ${ }^{(3)}$. Para que se produzcan dichos anticuerpos se necesitarían entre uno o dos semanas, tiempo en el cual se desarrollarían las manifestaciones, y esto es lo que comúnmente se reporta en este síndrome. Pero el tratar de hallar al agente etiológico en una patología que no es producida directamente por esta, equivale a buscar a Streptococcus pyogenes en cultivo de sangre para diagnosticar pericarditis por un síndrome post estreptococico, y justificarlo por el hecho que este tipo de cultivos son útiles para determinar endocarditis producida por Streptococcus viridans. Lo cual a todas luces sería inadecuado. La guía de vigilancia para Enterovirus de la OMS refiere que: "En algunos casos, los análisis serológicos pueden proporcionar importantes Información para confirmar la enfermedad asociada a enterovirus o determinar la extensión de brotes" (12). Opino que esta herramienta sería apropiada ya que requerimos confirmar la presencia del agente infeccioso con una o dos semanas de anticipación a la enfermedad, lo cual tendría que ser correlacionado con el hallazgo del virus en otras muestras clínicas. Debemos tener en cuenta que EV-D68, a diferencia de otros enterovirus se detecta 
difícilmente en heces debido a que su sitio diana se encuentra en fosas nasales y tiene labilidad a los ácidos del estómago, por lo que se comporta más como un virus respiratorio y su detección en estas zonas sería de mayor utilidad ${ }^{(13) .}$

Tenemos que tener cuidado al intentar justificar algún hallazgo de laboratorio, modificando información de estudios o interpretándolos de forma intencional, lo cual podría caer en falsedad científica. Lo cierto es que en el mundo (según la revisión realizada) no hay evidencia que relacione firmemente al SGB con infecciones producidas por EV-D68 ni con otro tipo de enterovirus, y aunque en la última década se han registrado brotes de estos asociados a patologías neurológicas como AFM, no ha sido así con el SGB, el cual se presenta con una distinta fisiopatología. Por ello, resalta la necesidad de un trabajo integrado entre especialistas en las áreas de microbiología, infectología y neurología, si queremos investigar sobre una causa infecciosa del SGB. Es muy probable por el patrón estacionario, la amplia distribución geográfica y el número inusual de casos, que este brote se encuentre relacionado con algún agente infeccioso principalmente de origen viral; sin embargo, tenemos que definir correctamente los casos y elegir adecuadamente las pruebas de laboratorio que nos permitan sacar oportunas conclusiones.

\section{REFERENCIAS BIBLIOGRÁFICAS}

1. La República. Enterovirus D68:posible causante de los casos de GuillainBarr [Internet].2019 [cited 2019 Jun 23]. Avai lable from: https://larepublica. pe/sociedad/1240637-enterovirus-d68-posible-causante-casos-guillain-barre/

2. OMS. Síndrome de Guillain-Barré [Internet]. 2016 [cited 2019 Jun 23]. Available from: https://www.who.int/es/news-room/fact-sheets/detail/guillain-barré-syndrome

3. Donofrio PD. Guillain-Barré Syndrome. Contin Lifelong Learn Neurol. 2017;23(5, Peripheral Nerve and Motor Neuron Disorders):1295-309.

4. Greene SK, Rett MD, Vellozzi C, Li L, Kulldorff M, Marcy SM, et al. Guillain-Barré Syndrome, Influenza Vaccination, and Antecedent Respiratory and Gastrointestinal Infections: A Case-Centered Analysis in the Vaccine Safety Datalink, 2009-2011. Park M-S, editor. PLoS One [Internet]. 2013 Jun 26 [cited 2019 Jun 23];8(6):e67185. Available from: https://dx.plos.org/10.1371/ journal.pone.0067185

5. Vigilancia en Salud Pública - Hospitales de Perú en alerta por Síndrome de Guillain Barré [Internet]. 2018 [cited 2019 Jun 23]. Available from: https:// temas.sld.cu/vigilanciaensalud/2018/05/10/hospitales-de-peru-en-alerta-por-sindrome-de-guillain-barre/

6. Resolución_Directoral_N177-2018-DG-HEJCU. plan de contingencia para atención de pacientes sospechosos de síndrome de Guillain Barrè del Hospital de emergencias :Josè Casimiro Ulloa [Internet]. Lima; 2018 [cited 2019 Jul 8]. Available from: http://www.hejcu.gob.pe/PortalTransparencia/Archivos/Contenido/0107/Resolución_Directoral_N177-2018-DG-HEJCU_Plan_ de_Contingencia_Guillan_Barre.PDF

7. Jacobs $B C$, Rothbarth PH, van der Meché FG, Herbrink P, Schmitz PI, de Klerk MA, et al. The spectrum of antecedent infections in Guillain-Barré syndrome: a case-control study. Neurology [Internet]. 1998 Oct [cited 2019 Jun 23];51(4):1110-5. Available from: http://www.ncbi.nlm.nih.gov/pubmed/9781538

8. Williams CJ, Thomas RH, Pickersgill TP, Lyons M, Lowe G, Stiff RE, et al. Cluster of atypical adult Guillain-Barré syndrome temporally associated with neurological illness due to EV-D68 in children, South Wales, United Kingdom, October 2015 to January 2016. Eurosurveillance [Internet]. 2016 Jan 28 [cited 2019 Jun 23];21(4):30119. Available from: http://www.ncbi.nlm.nih. gov/pubmed/26848143

9. Maloney JA, Mirsky DM, Messacar K, Dominguez SR, Schreiner T, Sten- ce NV. MRI Findings in Children with Acute Flaccid Paralysis and Cranial Nerve Dysfunction Occurring during the 2014 Enterovirus D68 Outbreak. Am J Neuroradiol [Internet]. 2015 Feb [cited 2019 Jun 23];36(2):245-50. Available from: http://www.ncbi.nlm.nih.gov/pubmed/25414005

10. Dyda A, Stelzer-Braid S, Adam D, Chughtai AA, Maclntyre CR. The association between acute flaccid myelitis (AFM) and Enterovirus D68 (EVD68) - what is the evidence for causation? Euro Surveill [Internet]. 2018 [cited 2019 Jun 23];23(3). Available from: http://www.ncbi.nlm.nih.gov/ pubmed/29386095

11. Nelson GR, Bonkowsky JL, Doll E, Green M, Hedlund GL, Moore KR, et al. Recognition and Management of Acute Flaccid Myelitis in Children. Pediatr Neurol [Internet]. 2016 Feb [cited 2019 Jun 24];55:17-21. Available from: http://www.ncbi.nlm.nih.gov/pubmed/26621554

12. World Health Organization. Enterovirus surveillance guidelines. 2015; Available from: http://www.euro.who.int/_data/assets/pdf_file/0020/272810/ EnterovirusSurveillanceGuidelines.pdf

13. Cassidy H, Poelman R, Knoester M, Leer-Buter CC Van, Niesters HGM. Enterovirus D68 - The New Polio? Front Microbiol [Internet]. 2018 [cited 2019 Jul 9];9. Available from: https://www.ncbi.nlm.nih.gov/pmc/articles/ PMC6243117/

Revisión de pares: Recibido: 26 / 06 / 2019 Aceptado: 18/ 07/ 2019 